\title{
SABERES DOCENTES NA EDUCAÇÃO PROFISSIONAL TÉCNICA DE NÍVEL MÉDIO: UMA PROPOSTA PARA A FORMAÇÃO DE PROFESSORES DO IFAM - CAMPUS LÁBREA
}

\author{
Antonio Paulino dos Santos ${ }^{1}$ e Rosa Oliveira Marins Azevedo ${ }^{2}$ \\ ${ }^{1}$ Instituto Federal de Educação, Ciência e Tecnologia do Amazonas - paulioventura@yahoo.com.br; \\ ${ }^{2}$ Instituto Federal de Educação, Ciência e Tecnologia do Amazonas - marinsrosa@yahoo.com.br
}

Artigo submetido em maio/2016 e aceito em outubro/2016

DOI: $10.15628 /$ rbept.2016.4503

\section{RESUMO}

Este trabalho tem o objetivo de apresentar os conceitos iniciais à compreensão da tecnologia e como ela deve ser usada para a realização de uma Educação Profissional mais humanizada. Abordará a Lei de Diretrizes e Bases da Educação e a organização da Educação Profissional Técnica de Nível Médio, bem como disponibilizar conhecimento acerca das tendências para a formação de professores, com ênfase aos Saberes Docentes elencados por Maurice Tardif. A metodologia utilizada foi leitura de literatura especializada (livros e artigos), fichamentos, sínteses e resenhas realizadas durante a disciplina
'Fundamentos para a Formação de Professores no Ensino Tecnológico', do Programa de Mestrado Profissional em Ensino Tecnológico (MPET) do Instituto Federal de Educação, Ciência e Tecnologia do Amazonas (IFAM). O estudo mostra a necessidade de uma Educação Profissional mais humanizada na formação de professores do IFAM - Campus Lábrea e propõe a inserção de novos saberes para as práticas docentes, almejando o desenvolvimento da Educação Profissional Técnica de Nível Médio.

PALAVRAS-CHAVE: Educação Profissional Técnica de Nível Médio, Saberes Docentes, Formação de Professores.

\section{KNOWLEDGE TEACHERS IN VOCATIONAL EDUCATION TECHNIQUE MIDDLE LEVEL: A PROPOSAL FOR TEACHER TRAINING OF IFAM - CAMPUS LÁBREA}

\begin{abstract}
This study aims to present the initial concepts to the understanding of technology and how it should be used for the realization of a more humanized Education Professional. Address the Law of Guidelines and Bases of Education and the Organization of Vocational Education High School Technical and provide knowledge about the trends for teacher training, with emphasis on Knowledge Professors listed by Maurice Tardif. The methodology used was literature reading (books and articles) records, syntheses and reviews conducted during the course
\end{abstract}

'Foundations for Teacher Training in Technological Education', the Professional Master's Program in Technological Education (MPET) of the Federal Institute education, Science and Technology of Amazonas (IFAM). The study shows the need for more humane education professionals in the training of teachers IFAM - Campus Lábrea and proposes the inclusion of new knowledge for teaching practices, aiming for the development of Vocational Education High School Technical.

KEYWORDS: Education Vocational High School Technical, Knowledge Teachers, Teacher Training. 


\section{INTRODUÇÃO}

O presente artigo é resultante da socialização, dos debates, discussões e atividades realizadas no âmbito da disciplina 'Fundamentos para a Formação de Professores no Ensino Tecnológico', do Programa de Mestrado Profissional em Ensino Tecnológico (MPET) do Instituto Federal de Educação, Ciência e Tecnologia do Amazonas (IFAM), através da leitura, fichamentos, sínteses e resenhas de literatura especializada (livros e artigos).

De forma geral, o objetivo do trabalho é apresentar conceitos relacionados à Tecnologia e seus fundamentos iniciais direcionados como forma de possibilitar uma Educação Profissional mais humanizada. A discussão perpassa a estrutura da Educação Profissional Técnica de Nível Médio no Brasil, associando-a às tendências para a formação de professores no âmbito do IFAM - Campus Lábrea, através de uma proposta para a consecução dos Saberes Docentes como contribuição à concepção de novos saberes que possa viabilizar e/ou aperfeiçoar as práticas pedagógicas desses docentes.

O trabalho foi organizado em três (3) seções. Na seção 1 serão apresentados os primeiros passos para a compreensão da Tecnologia com vistas a uma Educação Profissional humanizada, com o uso dos recursos tecnológicos como meio de desenvolvimento do bem comum, bem como a construção de um paralelo entre a Lei de Diretrizes e Bases da Educação (LDB) e a Educação Profissional Técnica de Nível Médio (EPTNM), objetivando o conhecimento do sistema de ensino no Brasil e a organização da EPTNM como um todo.

Na seção 2, serão mostradas as principais tendências para a formação de professores e abordada com maior ênfase a tendência de Saberes Docentes na visão de Maurice Tardif, com as devidas explanações acerca do conceito de Saber e do papel do Professor, visando um debate inicial indispensável nas instituições de Educação Profissional.

Na seção 3, serão discutidas as similaridades entre a Tecnologia, a EPTNM e a tendência Saberes Docentes para a formação de professores, o que culminará com proposta viável de formação para os professores do Instituto Federal de Educação, Ciência e Tecnologia do Amazonas (IFAM) - Campus Lábrea.

Para finalizar o trabalho, serão apresentadas as considerações finais, munidas das principais questões levantadas para a sequência da pesquisa, para a construção de novas propostas nas instituições de Educação Profissional e finalmente, as referências utilizadas para a concepção do estudo.

\section{OS PRIMEIROS PASSOS PARA A COMPREENSÃO DA TECNOLOGIA COM VISTAS A UMA EDUCAÇÃO PROFISSIONAL HUMANIZADA}

Diante de todos os acontecimentos que permeiam a sociedade nos dias atuais aquele que merece mais a nossa atenção é a chamada Tecnologia. O que é? Como nasceu? Do que trata? Quais 
seus benefícios e malefícios ao ser humano? E para responder a essas e outras questões necessitamos nos debruçar em autores que tratam a temática visando formalizar um conceito de tecnologia e partindo desse pressuposto, ter uma noção da realidade tecnológica estabelecida.

Como passo inicial, é notório destacar que os primórdios do que é tido no senso comum como tecnologia trata-se, na verdade, de um processo que vem de um desenvolvimento histórico, conforme nos apresenta Veraszto (2004, s/p):

[...] é através de um estudo da evolução histórica das técnicas desenvolvidas pelo homem, colocadas dentro dos contextos sócio-culturais de cada época, é que podemos compreender melhor a participação ativa do homem e da tecnologia no desenvolvimento e no progresso da sociedade, enriquecendo assim o conceito que temos a respeito do termo tecnologia.

Nossos antepassados já dispunham de certas técnicas para resolver determinadas situações do cotidiano, mas no momento em que aliou seu pensamento à capacidade de transformação deu início à modificação do meio (VERASZTO et al, 2008). Diante desse aspecto, "[...] se cultiva tanto a natureza humana, com vistas ao desenvolvimento pessoal e dela própria, quanto à natureza externa, em que se situa a atividade produtiva, a qual gera a tecnologia" (SILVA, 2013, p. 842).

Tanto aperfeiçoamento acabou gerando na sociedade uma constante mudança: a associação de toda atividade produtiva sendo executada pelas máquinas (PEÑA; ALVES E PEPPE, 2003, p. 10). Mesmo imperceptível ao ser humano fanático, dada à mistificação que submete às máquinas e outros artefatos, problemas sociais significativos afetam a muitos: desemprego, pobreza e dependência cada vez maior daquilo que não é humano.

Essa premissa é confirmada por Adorno (1995, p. 132), quando exemplifica que:

[...] é preciso examinar também a relação com a técnica, sem restringir-se a pequenos grupos. [...] Por um lado, é certo que todas as épocas produzem as personalidades - tipos de distribuição da energia psíquica - de que necessitam socialmente. Um mundo em que a técnica ocupa uma posição tão decisiva como acontece atualmente, gera pessoas tecnológicas, afinadas com a técnica.

Somos levados, dessa forma, a agir como se não fizéssemos parte da natureza, como se não pertencêssemos a essa realidade e construímos os nossos protetores sistemas tecnológicos: roupas, medicamentos, laptops e outros símbolos. (BAZZO; BAZZO; PEREIRA, 2014). O que se configura como implementação de artefatos que perdem suas características de usabilidade e adquirem uma representatividade comportamental e de constituição de ter e de poder.

Necessitamos urgentemente entender a "[...] extraordinária proliferação da tecnologia, apossando-se de quase todos os aspectos da existência humana" (PINTO, 2005) como algo que precisa ser compreendida em seu bojo conceitual a fim de que possamos utilizar seus recursos para o bem comum.

Para tanto se faz necessário buscar uma maior equidade de distribuição de renda e socialização de acesso aos frutos do desenvolvimento e uma educação mais reflexiva. Em 
especial nas escolas que trabalham a tecnologia. E nessa perspectiva temos que ser pluralistas para incrementar um processo educacional intensivo onde os avanços tecnológicos sejam difundidos, discutidos, assimilados e, e em certas situações, reprocessados internamente e integrados à cultura nacional. (BAZZO, 2001, p. 13).

Se a tecnologia é, pois, capaz de possibilitar a reconstrução das relações humanas, cabe à escola implementar uma Educação Profissional cuja formação

\begin{abstract}
[...] não deve limitar-se apenas à transmissão de conhecimentos referentes a habilidades técnicas e à capacidade de saber executar tarefas e procedimentos. Outros fatores, como formar para a cidadania, saber desenvolver, lidar e se adaptar às novas tecnologias, adquirir competências necessárias para a atual competitividade do mundo do trabalho, para saber viver em sociedade, para saber viver em família, para buscar uma sociedade justa, enfim, competências necessárias para se tornar um ser humano que saiba buscar o equilíbrio nos diversos campos de sua vida, desenvolver uma capacidade crítica de se posicionar diante dos acontecimentos econômicos, políticos, sociais e tecnológicos, desenvolver o bom relacionamento interpessoal, a criatividade e o debate acerca de questões éticas, também devem ser valorizados." (DURÃES, 2009, p. 168-169)
\end{abstract}

Para tanto, há de se levar em consideração os preceitos estabelecidos por Bazzo (2001, p.16), da educação que se faz não apenas dentro da escola:

O que se propõe é uma educação que extrapole os muros da escola em todos os níveis, alcançando a sociedade na sua plenitude envolvendo aqueles que tem acesso quanto aqueles que não tem acesso aos bancos escolares, tendo como intento ampliar e aprofundar o diálogo com as ciências sociais, levando à reflexão e a transformação cultural frente os avanços tecnológicos.

Dessa forma é possível, a nosso ver, compreender a tecnologia como o conjunto de saberes do homem, adquiridos através de técnicas manifestadas na construção de artefatos não apenas funcionais, mas de valores meramente simbólicos, cujo intuito é o aperfeiçoamento às atividades humanas.

Para tornar o progresso tecnológico mais humanizado com todos esses recursos sendo utilizados como alternativa para o processo ensino-aprendizagem, todas as reflexões necessárias passam pela Educação, permitindo que cada ser humano participe de forma direta das discussões para a implementação e/ou dos rumos da tecnologia, a começar por compreender a composição do sistema de ensino disponibilizado nos país.

\title{
2.1 A lei de diretrizes e bases da educação e a educação profissional técnica de nível médio
}

A Lei de Diretrizes e Bases da Educação Nacional, Lei Federal no 9.394/1996, também chamada Lei Darcy Ribeiro (em homenagem ao senador relator da matéria) ou simplesmente LDB, estabeleceu no Brasil as diretrizes e bases da educação nacional, trazendo várias mudanças em relação a suas antecessoras. 
Essa lei estruturou o ensino no Brasil em dois grupos principais: Educação Básica (que compreende a Educação Infantil, o Ensino Fundamental e o Ensino Médio) e Educação Superior (Graduação: Bacharelado/Licenciaturas e Pós-graduação: Mestrado/Doutorado).

A Educação Profissional e Tecnológica (EPT), nos termos da LDB com alteração realizada pela Lei $n$ o 11.741/2008, abrange os cursos de:

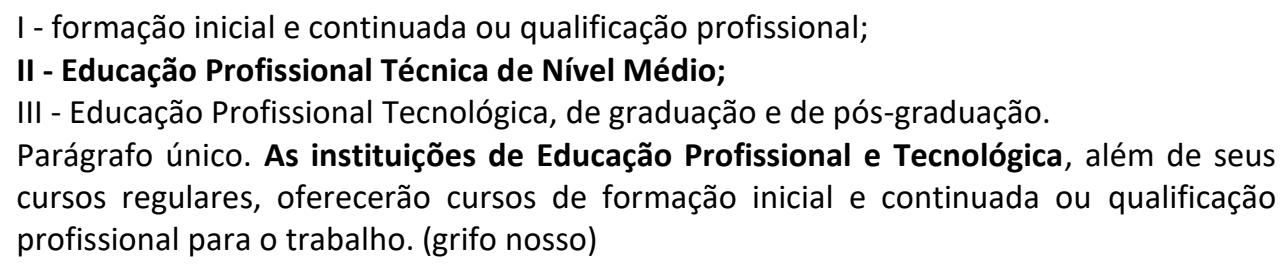

A Educação Profissional e Tecnológica (EPT) está, portanto, subdividida no âmbito do Ensino Médio com a denominação de Educação Profissional Técnica de Nível Médio (EPTNM) e no âmbito superior intitulada Educação Profissional Tecnológica, de graduação e de Pós-graduação (BRASIL, 2012).

A Resolução no 6, de 20 de setembro de 2012 (CNE/CEB), que define as Diretrizes Curriculares Nacionais para a Educação Profissional Técnica de Nível Médio, em seu Art. 3o explicita que "[...] a Educação Profissional Técnica de Nível Médio é desenvolvida nas formas articulada e subsequente ao Ensino Médio, podendo a primeira ser integrada ou concomitante a essa etapa da Educação Básica".

É possível compreender que na EPTNM é realizada a Educação Profissional integrada ao Ensino Médio, onde os estudantes adquirem os conhecimentos propedêuticos dessa modalidade de ensino e mais as disciplinas de formação técnica na mesma instituição (Integrada ao Ensino Médio) ou em outra instituição (Concomitante). Para os alunos concludentes do Ensino Médio é ofertada a modalidade Subsequente (basicamente com as disciplinas da área técnica).

Realizadas as considerações acerca da estrutura do ensino no Brasil e apresentada a abrangência da Educação Profissional Técnica de Nível Médio, é possível realizar o discernimento que

[...] consideraremos como educação técnica aquela que corresponde a uma formação restrita, em que o aluno é capacitado para executar tarefas, aprender técnicas de um dado ofício e/ou de uma profissão, manusear máquinas e equipamentos e, quando muito, conhecer os direitos e os deveres que o mundo do trabalho atribui ao trabalhador (DURÃES, 2009, p. 169).

Essa preocupação com a formação do estudante para o mundo do trabalho com desenvolvimento pleno é um dos princípios norteadores da EPTNM quando as Diretrizes Nacionais Curriculares estabelecem em seu Art. 60:

\footnotetext{
II - respeito aos valores estéticos, políticos e éticos da educação nacional, na perspectiva do desenvolvimento para a vida social e profissional;

III - trabalho assumido como princípio educativo, tendo sua integração com a ciência, a tecnologia e a cultura como base da proposta politico-pedagógico e do desenvolvimento curricular;
} 
VI-indissociabilidade entre teoria e prática no processo de ensino-aprendizagem;

$X V$ - identidade dos perfis profissionais de conclusão de curso, que contemplem conhecimentos, competências e saberes profissionais requeridos pela natureza do trabalho, pelo desenvolvimento tecnológico e pelas demandas sociais, econômicas e ambientais. (BRASIL, 2012, p. 2 - 3).

que corrobora para que o estudante adquira os conhecimentos necessários para além das práticas exigidas pelo mundo do trabalho e estará apto a atuar com criticidade diante da sociedade atual, enaltecendo que

É esta relação do trabalho com a educação que nos permite entender que, a preparação técnica para o trabalho não é desvinculada da mediação entre projetos de desenvolvimento da justiça social, da efetivação da igualdade social e cultural, da busca pela democratização da cidadania e as bases técnicas da produção e preparação para o mercado de trabalho. (BAPTAGLIN, 2013, p. 7712)

Para tanto, continuaremos a discussão a partir dos servidores docentes, visualizando suas práticas e entendendo seus conhecimentos então acumulados durante o tempo, a partir dos estudos necessários à tendência de formação de professores, com ênfase aos Saberes Docentes.

\title{
3. AS TENDÊNCIAS PARA A FORMAÇÃO DE PROFESSORES
}

A ressignificação dos Institutos Federais a partir da consolidação da Educação Profissional Técnica de Nível Médio (EPTNM) depende de cada ator partícipe, porém, de modo especial situaremos o professor como colaborador desse viés, a partir das respostas aos questionamentos de Souza (2015, p. 18):

\begin{abstract}
Sou capaz de empreender um novo modelo educativo-pedagógico pautado na práxis, no diálogo, na problematização e na ética humana? [...] Pretendo formar pessoas criticocontestadoras, capazes de se transformarem e transformarem a sociedade em que vivem, ou quero continuar modelando sujeitos passivos, satisfeitos com as migalhas da mediocridade?
\end{abstract}

Porém, para que ele responda a todos os questionamentos apresentados, além de muitos outros, que se fazem necessários nos dias atuais é imprescindível um conhecimento acerca das tendências para a formação de professores.

As tendências, na visão de Ghedin (2009, p. 3), são "um conjunto de características diferenciadas que possibilitam identificar o desenvolvimento de uma determinada perspectiva de formação para professores". São quatro (4) as tendências mais difundidas no Brasil, cujos conceitos centrais são: saber docente, reflexão sobre a prática, pesquisa no ensino e competências da formação (GHEDIN, 2009, p. 4).

Conforme Santos, Azevedo e Gonzaga (2015, p. 3): 
Os saberes [...] aparece como elemento fundamental no processo formativo do professor. A pesquisa [...] possibilita ao professor, a relação com o saber já consolidado [...]. A reflexão é vista como uma resposta do ser humano ao desafio da realidade. [...] e a tendência das Competências [...] a serviço de ideologias que reduzem o papel da educação e da atuação docente a um mero trabalho técnico. [...]

De qualquer forma, cada uma dessas tendências necessita ser estudada com afinco, observando-se os principais autores nacionais e internacionais que debatem a matéria e a partir daí proceder na prática, conforme a realidade local. Nesse aspecto, intensificaremos os estudos na tendência de Saberes Docentes.

\subsection{A visão geral dos Saberes Docentes, o papel do professor e o conceito de saber}

O professor, em seu trabalho diário, lida com as mais variadas tarefas: planejar aula, definir as práticas pedagógicas, administrar a sala de aula, manter a ordem e a disciplina, compreender os aspectos que envolvem o processo ensino-aprendizagem, dentre outros. Para isso, ele precisa dispor de uma série de conhecimentos obtidos durante sua vivência acadêmica, familiar, comunitária e na sociedade como um todo.

Em Saberes Docentes, o professor é apresentado como “[...] um profissional que detém saberes de variadas matizes sobre a educação e tem como função principal educar crianças, jovens e adultos" (CUNHA, 2007, p. 34), e de posse do conhecimento dessas matizes e dos saberes poderá adquirir o suporte necessário para seu trabalho cotidiano.

Para Cunha (2007, p. 34), o saber

[...] é a consequência de uma atividade intelectual, presente nos discursos que apresentam um juízo verdadeiro sobre um objeto, um fenômeno, essa concepção associa o saber ao juízo. Outra concepção considera o saber como uma atividade capaz de apresentar razões por meio da lógica, dialética e da retórica. [...] Segundo esse aspecto o saber encontra-se também no discurso normativo.

"O professor, para que seja um profissional qualificado deve dominar um conjunto de saberes que se constitui de práticas e de experiência da própria atuação profissional que iluminam e condicionam as nossas decisões ao longo do processo de ensino". (GHEDIN, 2009, p.7).

Nosso papel é empreender esforços para verificar quais são esses saberes e utilizá-los no ambiente escolar à medida que contribuam para a melhoria das práticas pedagógicas dos docentes.

Nesse contexto, enfatizamos que diversos autores pesquisam acerca dos Saberes Docentes: Tardif, Pimenta, Gauthier, Saviani, conforme tabela a seguir. 
Tabela 1: Categorização dos saberes docentes.

\begin{tabular}{|c|c|c|c|}
\hline Tardif et al (1991) & Pimenta (1999) & Gauthier et al (1998) & Saviani (1996) \\
\hline $\begin{array}{l}\text { 1. saberes da formação } \\
\text { profissional } \\
\text { 2. saberes das disciplinas } \\
\text { 3. saberes curriculares } \\
\text { 4. saberes da experiência }\end{array}$ & $\begin{array}{l}\text { 1. saberes da experiência } \\
\text { 2. saberes do } \\
\text { conhecimento } \\
\text { 3. saberes pedagógicos }\end{array}$ & $\begin{array}{l}\text { 1. saberes disciplinares } \\
\text { 2. saberes curriculares } \\
\text { 3. saberes das Ciências da } \\
\text { Educação } \\
\text { 4. saberes da tradição } \\
\text { pedagógica } \\
\text { 5. saberes experienciais } \\
\text { 6. saberes da ação } \\
\text { pedagógica }\end{array}$ & $\begin{array}{l}\text { 1. saber atitudinal } \\
\text { 2. saber crítico- } \\
\text { contextual } \\
\text { 3. saber específico } \\
\text { 4. saber pedagógico } \\
\text { 5. saber didático- } \\
\text { curricular }\end{array}$ \\
\hline
\end{tabular}

Cada autor, no entanto, utiliza-se de conceitos próprios para explicar sua categorização para os Saberes Docentes. Neste estudo vamos adotar as concepções de Maurice Tardif.

\subsection{Os saberes docentes na concepção de Maurice Tardif}

O nome de maior expressão na tendência de Saberes Docentes é o do professorpesquisador canadense Maurice Tardif, da Universidade de Laval, Quebec, e da Universidade de Montreal, onde dirige pesquisas voltadas para a evolução e situação da profissão docente, além, da formação de professores e dos conhecimentos de base da docência. (PREZI, 2016)

A tendência surgiu "[...] na realidade brasileira, a partir da década de 1990" (CUNHA, 2007, p. 32), durante os debates acerca da profissionalização do ensino e da docência e se intensificou com a publicação do livro 'Saberes Docentes e Formação Profissional', de Tardif, em 2002.

Ela é caracterizada pelo conjunto dos saberes utilizados pelos docentes em seu espaço de trabalho cotidiano para desempenhar todas as suas tarefas (TARDIF, 2002, p. 10), numa alusão de que todo conhecimento adquirido pelo profissional ao longo de sua vida tem relevância para sua atuação em sala de aula, baseando-se nos saberes da formação profissional, das disciplinas, curriculares e da experiência.

- Saberes da formação profissional (são aqueles comuns a todas as áreas da educação: Filosofia, Psicologia, Didática Geral...). Essas áreas são importantes para que o professor adquira o entendimento necessário para atuar nas mais diversas situações no ambiente de sala de aula, articulando teoria e prática;

- Saberes da disciplina (são as áreas específicas de cada formação: Física, Matemática, Química...). São essenciais para a atuação do professor em sala de aula na construção do conhecimento específico. 
- Saberes curriculares (adquiridos quando inserido na escola: Parâmetros Curriculares Nacionais, Legislação, Normativas, Resolução, Plano de Ensino, Base Nacional Comum...). Fundamentais para nortear o trabalho de gestão de sala de aula do professor e da instituição.

- Saberes da experiência (vivenciados nas práticas escolares e em sala de aula...). As experiências vivenciadas no cotidiano da sala de aula a partir da própria prática, as compartilhadas entre os pares, bem como as aquelas advindas da família, comunidade, em empregos anteriores.

Para o autor, merece especial destaque os Saberes da Experiência na medida em que

[...] resultam do próprio exercício da atividade profissional dos professores. [...] são produzidos pelos docentes por meio da vivência de situações específicas relacionadas ao espaço da escola e às relações estabelecidas com alunos e colegas de profissão (Tardif, $2004, s / p)$.

De posse dos conceitos principais e concepção de Saberes Docentes, é fundamental proceder ao conhecimento da formação de professores na perspectiva dessa tendência e como colocá-la em prática na realidade do IFAM - Campus Lábrea.

\section{A FORMAÇÃO DE PROFESSORES NA EDUCAÇÃO PROFISSIONAL TÉCNICA DE NÍVEL MÉDIO}

Há diversos entraves que necessitam ser enfrentados para a ressignificação da EPTNM no Brasil. Nos escritos de Moura (2008, p. 28) é possível compreender o grande desafio que a EPTNM tem, dentre outros, para cumprir a responsabilidade social que Ihe foi confiada

[...] diz respeito à responsabilidade social do campo da educação profissional com os sujeitos formados em todas as suas ofertas educativas e com a sociedade em geral. Referese, assim, ao poder da EPT de contribuir com o aumento da capacidade de (re)inserção social, laboral e política dos seus formandos; com a extensão de ofertas que contribuam à formação integral dos coletivos que procuram a escola pública de EPT para que esses sujeitos possam atuar, de forma competente e ética, como agentes de mudanças orientadas à satisfação das necessidades coletivas, notadamente as das classes trabalhadoras.

O que perpassa pela fundamental e responsável formação de professores, haja vista que essa responsabilidade social da EPTNM também depende dos esforços empreendidos por cada um dos docentes para

Superar o histórico de fragmentação, improviso e insuficiência de formação pedagógica que caracteriza a prática de muitos docentes da educação profissional de hoje implica reconhecer que a docência é muito mais que mera transmissão de conhecimentos empíricos ou processo de ensino de conteúdos fragmentados e esvaziados teoricamente. (MACHADO, 2008, p.15) 
Ao observamos que "[...] a carência de pessoal docente qualificado tem se constituído num dos pontos nevrálgicos mais importantes que estrangulam a expansão da educação profissional no país" (MACHADO, 2008, p. 14), é necessário que se realizem os debates necessários para a resolução deste impasse.

Por conseguinte, é possível começar a traçar um novo caminho, tendo em vista que foram feitos os esclarecimentos acerca das principais tendências para a formação de professores bem como com a apresentação dos principais pesquisadores, com ênfase nos Saberes Docentes, viabilizados pelo professor canadense Maurice Tardif, para quem o saber do professor:

[...] engloba os conhecimentos, as competências, as habilidades (ou aptidões) e as atitudes, isto é, aquilo que muitas vezes foi chamado de saber, saber-fazer e saber-ser. Sublinhemos, como mostraremos adiante, que esse sentido amplo reflete o que os próprios profissionais dizem a respeito de seus próprios saberes profissionais. (TARDIF; LESSARD, 1999, s/p).

No contexto da EPT, o professor deve assumir atitude crítica e reflexiva orientada para a responsabilidade social. Com isso, temos que fomentar uma formação inicial sólida e continuada de qualidade. "Os que participam da formação devem beneficiar-se de uma formação de qualidade que seja adequada a suas necessidades profissionais em contextos sociais e profissionais em evolução e que repercuta na qualidade do ensino." (IMBERNÓN, 2006, p. 98).

Para que essa formação possa ser efetivada na prática, é necessário, conforme Mancebo (2009. p. 233), observar que

[...] o mais importante é a passagem de um regime no qual predomine um tipo de relação pedagógica (seja ela transmissiva ou construtivista) para um regime em que se articulem diferentes tipos de relação, em razão de demandas próprias de cada contexto, as quais o professor tenha condições teórico-práticas de enfrentar.

Para tanto, é urgente "compreendermos que os saberes para a docência estão intimamente relacionados ao projeto de sociedade que se procura efetivar nos diversos momentos históricos ligados aos aspectos econômicos, políticos, culturais e sociais" (CAMPOS et al, 2015, p. 8).

Dessa forma, é possível empreender nossos esforços no sentido de formar professores evidenciando os importantes aspectos citados por Campos et al. $(2015$, p. 8):

[...] valorização da formação humana integral; diálogo com a sociedade com vistas à qualidade de vida; conhecimento do mundo do trabalho, de questões técnicas específicas; diálogo com o pensar e o fazer pedagógico, convergindo para a superação da dicotomia entre a teoria e a prática e a capacidade de reflexão sobre a prática.

Diante de todo o exposto, organizamos uma proposta para a formação de professores com vistas à aplicação dos Saberes Docentes na EPTNM, no IFAM - Campus Lábrea, o que se trata de uma tentativa inicial de utilização desses conceitos para a consecução de uma vivência prática efetiva. 


\title{
4.1 Uma proposta para a formação de professores do IFAM - Campus Lábrea na tendência dos saberes docentes
}

Geralmente, a formação de professores para a Educação Profissional Técnica de Nível Médio ainda não surte os efeitos desejados, no que concerne à expressiva expansão da Rede Federal de Educação Profissional, Científica e Tecnológica então ocorrida no país.

\begin{abstract}
[...] as reuniões e as discussões realizadas pela SETEC demonstram [...] que temos hoje, inúmeras iniciativas que visam esta qualificação profissional, mas que não dão conta das necessidades apresentadas. São feitas por programas especiais, cursos de pós-graduação, formação em serviço e formação à distância, mas poucas são as iniciativas em relação à criação de cursos de licenciatura que preparem de forma qualificada estes profissionais. (MACHADO, 2008, p. 15)
\end{abstract}

Dada tamanha expansão da Rede, como ofertar uma formação de professores, por exemplo, no Instituto Federal de Educação, Ciência e Tecnologia do Amazonas (IFAM) - Campus Lábrea?

É necessário entender que o "[...] município de Lábrea localiza-se no médio curso do rio Purus, na situação do centro sub-regional do Purus, ao sul do Estado do Amazonas, numa grande área de planície aluvial em plena Amazônia" (LÁBREA, 2014, p. 10). O Campus do município, pertence à expansão II e teve inauguração realizada em Fevereiro/2010.

O IFAM - Campus Lábrea possui em seu quadro funcional 42 (quarenta e dois) docentes (entre efetivos, temporários e substitutos), dos quais 27 (vinte e sete) são de outras cidades do Estado do Amazonas e/ou de outros Estados da Federação, o que reflete uma infinidade de saberes que necessitam ser compreendidos e trabalhados no ambiente escolar para se transformar em novos saberes à disposição de cada docente, visando o aperfeiçoamento das práticas pedagógicas.

É notório perceber a diversidade de saberes tendo em vista que o que torna cada um deles

[...] profissional do ensino é um processo formativo, adequado, pensado intencionalmente de uma determinada forma e ação, que permite intervir politicamente na organização da sociedade, considerando os limites históricos, sociais, políticos e também da nossa própria atuação. (GHEDIN, 2009, p.6).

Toda formação de professores para se tornar efetiva leva em consideração o ambiente no qual acontecem as experiências. Segundo Nóvoa (2009, s/p):

[...] a escola é o lugar da formação de professores, o espaço da análise partilhada das práticas, com acompanhamento sistemático de supervisão e reflexão sobre o trabalho docente, na construção de um conhecimento profissional; da valorização do trabalho em equipe e do exercício coletivo da profissão. 

de Nível Médio, apresenta que

[...] a formação inicial não esgota as possibilidades de qualificação profissional e desenvolvimento dos professores da Educação Profissional Técnica de Nível Médio, cabendo aos sistemas e às instituições de ensino a organização e viabilização de ações destinadas à formação continuada de professores. (BRASIL, 2012, p. 12).

Resultando na proposta de formação de um profissional docente através do compartilhamento das vivências individuais, com base nos saberes do cotidiano no próprio espaço educacional, proporcionando a construção de um conhecimento para o exercício da docência. E ainda as experiências vividas anteriormente ao exercício da docência, incluindo a vivencia familiar, das formações, do exercício profissional anterior e experiências de vida.

Assim, propomos uma formação de professores na tendência de Saberes Docentes, considerando as seguintes etapas para sua execução:

- Detectar, no IFAM - Campus Lábrea, uma problemática do cotidiano docente, advindo da experiência em sala de aula na sua prática pedagógica;

- Discutir coletivamente esse problema, abrindo espaço para o compartilhamento de outras experiências concernente a essa problemática, através da realização de um Grupo Focal ${ }^{1}$ entre os docentes do Campus;

- A partir dessa coleta de dados, pesquisar referenciais teóricos, alocados nos saberes (profissionais, disciplinares, curriculares e Experienciais) para examinar essa problemática;

- Propor a elaboração uma ação de intervenção nessa problemática;

- Implementar a ação no IFAM - Campus Lábrea;

- Analisar os resultados dessa experiência, considerando os referenciais teóricos que foram empregados, resultando em um saber, que se originou da experiência e retorna a experiência (prática).

Essa estrutura pode ser realizada tantas vezes quantas forem necessárias, visando a percepção dos saberes docentes que contribuirão para o desenvolvimento de novos saberes. Pode-se se ainda utilizar outras estratégias para discussões entre os docentes, tais como rodas de conversa ou narrativas. O importante, entretanto, é despertar no grupo a importância dos saberes docentes para o dinamismo das práticas docentes e aperfeiçoamento da EPTNM no IFAM Campus Lábrea.

\footnotetext{
${ }^{1}$ Grupo Focal é uma técnica de pesquisa que coleta de dados por meio das interações grupais ao se discutir um tópico especial sugerido pelo pesquisador. Como técnica, ocupa uma posição intermediária entre a observação participante e as entrevistas em profundidade. Assim a formação de um grupo focal objetiva discutir e compreender a dinâmica de determinada problemática, detectada pelo pesquisador. Colocando em ação os saberes, estratégias e competências dos docentes e lhe proporcionando a troca de experiências no desenvolvimento de suas práticas docentes e a reflexão sobre suas próprias práticas. (GODIN, 2003).
} 


\section{CONSIDERAÇÕES FINAIS}

O presente trabalho possibilitou uma compreensão inicial da tecnologia, associada à importância de uma educação mais humanizada, o que perpassa pelo conhecimento da Lei de Diretrizes e Bases da Educação Nacional e da legislação da Educação Profissional Técnica de Nível Médio.

$\mathrm{Na}$ abordagem das tendências para a formação de professores, elencaram-se os principais autores da temática, com ênfase em especial para os Saberes Docentes, de Maurice Tardif, além de tratar de maneira especial do papel do professor e do conceito de saber para a viabilização de novos saberes.

Posteriormente foi apresentada uma proposta de formação de professores, visando novas práticas docentes através das experiências de cada um dos docentes do IFAM - Campus Lábrea, na tendência do Saberes Docentes e da necessidade de implementarem-se esforços no sentido de realizar debates acerca dessa temática.

Salientamos que este trabalho é apenas o ponto inicial para outras discussões e propostas, o que colaborará de forma significativa para a desmistificação da EPTNM, no âmbito do IFAM Campus Lábrea, de outros Campi e até de outras instituições de Educação Profissional da rede privada.

A relevância do trabalho está no fato de que pouco vem sendo construído e debatido acerca da Educação Profissional e Tecnológica como um todo. Espera-se, com isso, que estudos correlatos possam ser realizados, haja vista que maiores resultados serão obtidos com a continuidade desta pesquisa e com o aprofundamento dos estudos no Mestrado Profissional em Ensino Tecnológico do Instituto Federal de Educação, Ciência e Tecnologia do Amazonas.

\section{REFERÊNCIAS}

1. ADORNO, Theodor W. Educação e emancipação. Rio de Janeiro: Paz e Terra, 1995.

2. BAPTAGLIN, Leila Adriana. A Educação Profissional e Tecnológica e a Aprendizagem da Docência: O que está sendo pesquisado nas produções acadêmico-científicas? CONGRESSO NACIONAL DE EDUCAÇÃO - (EDUCERE), 11., Anais... Pontifícia Universidade Católica UFSM, Curitiba, p. 2013.

3. BAZZO, W. A.; BAZZO, J. L. S.; PEREIRA, L. T. V. Conversando sobre a Educação Tecnológica. Florianópolis: Editora da UFSC, 2014.

4. BRASIL. Presidência da República. Casa Civil. Lei no 9.394, de 20 de dezembro de 1996. Estabelece as diretrizes e bases da educação nacional.

5.

. Presidência da República. Casa Civil. Lei no 11.741, de 16 de julho de 2008. Altera

dispositivos da Lei no 9.394, de 20 de dezembro de 1996, que estabelece as diretrizes e bases da educação nacional, para redimensionar, institucionalizar e integrar as ações da 
educação profissional técnica de nível médio, da educação de jovens e adultos e da educação profissional e tecnológica.

6. . Presidência da República. Casa Civil. Lei no 11.892, de 29 de dezembro de 2008. Institui a Rede Federal de Educação Profissional, Cientifica e Tecnológica.

7. Resolução n 6, de 20 de setembro de 2012. Define diretrizes curriculares para a Educação Profissional Técnica de Nível Médio (CNE/CEB). Diário Oficial [da] República Federativa do Brasil, Poder Executivo, Brasília, DF, 21 set. 2012. Seção 1, p. 22.

8. CAMPOS, Alessandra T.; (org). Os saberes docentes para a formação de professores de Educação Profissional e Tecnológica. EDUCITEC - Revista de Estudos e Pesquisas sobre a Educação Tecnológica (Manaus), v.1 n.1, p. 1-9, ano 2015.

9. CUNHA, Emmanuel R. Os saberes docentes ou saberes dos professores. Revista Cocar, Belém, v. 1, n. 2, p. 31-39, jul./dez., 2007.

10. DURÃES, Marina N. Educação Técnica e Educação Tecnológica: Múltiplos Significados no Contexto da Educação Profissional. Educação e Realidade, v.34, n.3, p. 159-175, set/dez 2009.

11. GHEDIN, Evandro. Tendências e dimensões da formação do professor na contemporaneidade. In: CONGRESSO NORTE PARANAENSE DE EDUCAÇÃO FÍSICA ESCOLAR, 4., 2009, Londrina. Anais... Londrina: EDUEL, 2009. p. 1-28.

12. GONDIM, S. M. G. Grupos focais como técnica de investigação Qualitativa: desafios metodológicos. Paidéia, v. 12, n. 24, p. 149-160, 2003.

13. IMBERNÓN, Francisco. Formação docente e profissional: formar-se para a mudança e a incerteza. 6. ed. São Paulo: Cortez, 2006.

14. LÁBREA, Instituto Federal do Amazonas - Campus. PDI: Plano de Desenvolvimento Institucional 2014-2018_Campus Lábrea. Lábrea, 2014.

15. MACHADO, Lucília Regina de S. Diferenciais inovadores na formação de professores para a educação profissional. Revista Brasileira de Educação Profissional e Tecnológica/ Ministério da Educação, Secretaria da Educação Profissional e Tecnológica. Brasília, v.1, n.1, p. $8-22,2008$.

16. MANCEBO, D. Tecnologia na Educação: uma questão de transformação ou de formação. Campinas, SP: Alínea, 2009.

17. MOURA, Dante Henrique. A formação de docentes para a educação profissional e tecnológica. Revista Brasileira de Educação Profissional e Tecnológica. Brasília, v.1, n.1, p. $25-38,2008$.

18. NÓVOA, A. Para uma formação de professores construída dentro da profissão. In: Professores: imagens do futuro presente. Lisboa: Educa, 2009.

19. PEÑA, M. D. J.; ALVES, M. R.; PEPPE, M. A. Educação, tecnologia e humanização. Caderno de pós-graduação em Educação, Artes e História da Cultura. São Paulo, v.3, n.1, p. 9-19, 2003.

20. PREZI. Biografia de Maurice Tardif. Disponível em https://prezi.com/bxcy1rmxydtl/maurice-tardif-saberes-escolares-e-saberesprofissionais/ acesso em: 04 abr. 2016.

21. SANTOS, Alzanira S.; AZEVEDO, Rosa Oliveira M.; GONZAGA, Amarildo G. Tendência dos Saberes na formação profissional do professor: um olhar a partir do ensino tecnológico. EDUCITEC - Revista de Estudos e Pesquisas sobre a Educação Tecnológica (Manaus). v.1 n.2, p. 1-8, ano 2015.

22. SILVA, Caetana Juracy Rezende. Institutos Federais: Lei 11.892, de 29/12/2008_Comentários e Reflexões. Brasília: Editora do IFRN, 2009. 
23. SILVA, Gildemarck C. Tecnologia, Educação e Tecnocentrismo: as contribuições de Álvaro Vieira Pinto. Revista Brasileira de Estudos Pedagógicos - RBEP (online), Brasília, v.94, n.238, p. 839-857, set./dez. 2013.

24. SOUZA, Elias Bezerra de. Reflexões para uma educação metacompetente. São Paulo: Scortecci, 2015.

25. TARDIF. Maurice. Saberes profissionais dos professores e conhecimentos universitários. Revista Brasileira de Educação, São Paulo, n. 13, p. 5-24, jan./abr., 2000.

26. TARDIF, Maurice. Saberes docente e formação profissional. 2. ed. Petrópolis: Vozes, 2002.

27. VERASZTO, E. V. Projeto Teckids: educação tecnológica no ensino fundamental. 2004. 184 f. Dissertação (Mestrado em Educação) - Faculdade de Educação, Universidade Estadual de Campinas, Campinas, 2004.

28. VERASZTO, E. V.; SILVA, D.; MIRANDA, N. A.; SIMON, F. O. Tecnologia: Buscando uma definição para o conceito. Revista de Ciências e Tecnologias de informação e Comunicação do CETAC.MEDIA, n.7, 2008. p. $60-85$. 